\title{
Models of Teacher Development for the Integration of ICT in the Classroom \\ Working Group 3.5
}

Chair: Toni Downes (AU)

Rapporteur: Margaret Niess (US)

Participants: Peter Albion (AU), Karen Biering (DK), Pam Bishop (AU), Owen Burgan (AU), Terry Cannings (US), Martin James (NZ), Holly Jobe (US), Viki Lawrence (NZ), Avril Loweless (UK), Minttu Ollila (FI), Thea van Os (AU), Teresia Volotinen (FI), Dilanthe Withanage (Sri Lanka)

Keywords: in-service training, integration of ICT, teacher education, teaching/practice, teacher training

\begin{abstract}
This professional group explored a range of pre-service teacher education and continuing professional development strategies undertaken in the countries/systems/institutions of the members. No single strategy was identified as best, rather a variety of strategies were found to meet the varying needs. Issues during design, implementation and evaluation of strategies for the effective implementation include time, money, leadership development, alignment of the goals of assessment and professional development, lifelong learning, motivating teachers, rewards and incentives, language barriers.
\end{abstract}

\section{INTRODUCTION}

A number of national reports identify critical factors for a more comprehensive and effective integration of ICT into schools to respond to an information society curriculum. While each reports uses different language and frameworks, in all a set of inter-related factors need attention to ensure effective application of ICT in schools and effective teacher development. Teacher development is now the focus of many national strategies (APEC 
1999). While much is known about effective teacher development (CERI 1998), implementation of effective strategies at the institutional and systemic level is often constrained by politics, finance and structures. Successful preservice and in-service strategies may be transferable in certain situations. This report identifies some of these successful endeavours.

\section{TEACHER DEVELOPMENT FRAMEWORKS}

Models of teacher development vary across pre-service teacher education and continuing professional development. Group members provided a range of examples from their own institutions on the more common strategies. They noted the increasing use of online resources, learning environments, discussion groups in foundation and curriculum-focused subjects, and the growing use of video in online and CDRom based resources that bring classroom case studies into campus classrooms. Online interactions between student teachers and students in schools were the least common strategy.

Group members reported successful projects in the US and Australia in which pre-service teachers have acted as technology mentors for university faculty or classroom teachers. In these, skills and motivation of both mentor and mentee were increased. Partnerships between schools and pre-service education providers have been effective in the UK where there is collaboration and shared responsibility for planning, feedback and assessment. Partnerships included shared training for faculty and teachers in the development of ICT practice. Other elements included ready access by student teacher and teacher educators to equipment and networks, and the time and resources to undertake the necessary curriculum development.

The following tables resulted from discussion by group members of lists generated by an Australian Study (Department of Education, Training and Youth Affairs). Table 1 identifies the elements within pre-service teacher education programmes. Overall, elements A, B, C, F, H, I, K and L were seen by the group as the more critical components and element $M$ as the critical success factor underpinning the success of all other elements. Table 2 lists both the CPD and Infrastructure strategic elements.

Table 1. Elements of models of ICT integration in pre-service teacher education programmes
A. Separate compulsory ICT subjects - skill acquisition
B. Separate compulsory ICT subjects - curriculum/pedagogy
C. Diffusion - modelling and use across course (with integration across various subjects)
D. ICT Electives - skill acquisition 
E. ICT Electives - curriculum/pedagogy

F. Face-to-face use with children expected as part of learning experience or assessment tasks within particular subjects

G. Online use with children expected as part of learning experience or assessment tasks within particular subjects

H. Planning, teaching and evaluation of use of ICT for learning expected as part of professional experience requirement

I. Modelling by classroom teacher expected as part of professional experience

J. Online collaborative/team interactions with students in schools for projects/learning virtual practicums

K. Online interactions with teachers/professional communities as part of core learning experiences

L. Partnerships with schools so that student teachers, classroom teachers and teacher educators engage in inquiry or development projects around the use of ICT for teaching and learning

M. Faculty professional development

N. Flexible delivery, student-centered approaches to teaching and learning

O. Partnerships with industry: curriculum/software development programmes

Advantages such as 'being connected to the daily classroom work of teachers' or 'just-in-time assistance' were often juxtaposed against issues of time, cost and the increased workload of teachers. Using a mixture of elements maximised the advantages.

Members of the group provided some examples. At a national level, Sri Lanka has a national policy on IT (Withange 2001. The strategy aims to develop the human resource and physical infrastructure for teacher training through three levels - national, provincial and zonal - cascading out to each. From training lecturers at Universities and the National Colleges of Education, train the trainer programmes and out to the school level, all based on 10 intitial national trainers casacading their skills out to each level.

At the systemic level in several Pennsylvania (US) districts, groups of teachers worked designing technology-rich lessons for 'difficult to learn' maths concepts. Each teacher had a laptop, an email account and access to a

Table 2. Elements of models of continuing professional development programmes
Professional development strategies
A. Face-to-face single events within workplace
B. Face-to-face single events external to workplace
C. Face-to-face sequential multiple-event courses within workplace
D. Face-to-face sequential multiple-event courses external to workplace
E. University accredited courses 

F. Online single events
G. Online sequential multiple-event courses
H. Within workplace mentor programmes
I. Online mentor programmes
J. Teacher visits/exchanges
K. Curriculum or materials development projects
L. Collaborative topic-based teaching projects
M. Professional learning community projects/study groups
N. Sustained inquiry/action or teacher research projects

\section{Infrastructure components}
A. Funds for self-directed formal professional development
B. Central and advisory services
C. Teachers centres
O. Navigator/Lighthouse schools offering mentoring, practicums, courses
P. Allocation of specialist staff to schools - Professional Development Coordinator
D. Development and provision of resources
E. Provision and support for hardware etc. to teachers
Q. Partnerships with teacher education institutions around practicum and induction of beginning teachers
F. Partnerships with industry and other organisations
G. Provision of teacher release
H. Recognition and certification of learning/expertise
I. Incentives and rewards for minimum standards
J. Incentives and rewards for excellence/best practice

to a project listserv. Teachers met staff from their own and other school districts, tested their lessons with their students and another teacher, not in the project, tested the lesson design and materials. Another example is a group of Finnish teachers in the Netlibris Virtual Literature Circles project, part of the Virtual School project of the National Board of Education. A typical Netlibris teacher is primarily interested in literature; they meet, teamteach and support each other in a variety of ways. The new ICT component proceeds in small steps, the teachers working at first online in virtual literature circles 'as students', and then teaching collaboratively a mixed group of students. Team teaching and sharing students and responsibilities increases pedagogic awareness and commitment. A further example is the Teaching Futures project in Australia,. aiming to link school planning and pedagogy, which will incorporate ICT in new discussions towards a sense of shared leadership and a school wide pedagogy. 
One example from the school level came from Victoria, Australia. One school used of 'in house' expertise and invited experts to conduct whole day and after school workshops on skill development, including ICT. Universities continue to provide CPD through postgraduate courses. Since the mid 1980's Faculties of Education in many countries, including ones like Sri Lanka, have offered postgraduate programmes in educational use of ICT.

\section{ISSUES}

Many issues are critical to sustaining effective teacher development.

\subsection{Leadership development}

Educational leaders need to foster a school culture conducive for teacher development. Key elements include distribution of resources, technical support and personnel to assist teachers in implementing what they have learned. A key strategy for supportive school cultures is the provision of parallel development/in-service opportunities for educational leaders. As one example, Pennsylvania, US, has initiated technology leadership academies for school superintendents, school boards and principals. These academies develop capacity to lead the implementation of technology-rich, learnercentred learning environments and to support ongoing teacher development.

\subsection{Lack of time}

Schools are constantly faced with a lack of time. New initiatives first add to existing workload due to unfamiliarity with new systems and processes. Some schools have worked to replace, rather than add to, teacher workload by restructuring curriculum delivery to an integrated format that meets many curriculum requirements simultaneously; restructuring assessments to include student self evaluation and multiple curriculum assessment tasks; using digital planning and assessment software to reduce duplication; and using ICT for administrative tasks so maximising meetings for CPD.

\subsection{Motivation and life-long learning of the teacher}

The issues of life long learning and motivating the reluctant teacher closely linked and interrelated. Those delivering CPD must find the key to excite and encourage teachers on their journey along the learning continuum. This key may appeal to teachers' professional lives through the subject 
matter or personal interest. Robert Kramer Rasmussen from LegoDacta, during his keynote address at WCCE 2001, emphasised that learning should be 'Hard Fun'. The learner should be presented with sufficient challenges to make the learning interesting and their skills develop; once in balance, the learner can enter a 'flow' of continuing learning. For this flow to occur a number of key features should be present.

- Multi-professional groups with various expertise join collaboratively to develop an environment - all support each other and share knowledge.

- Continuing dynamic dialogue between research and classroom practice and experiences of those involved in the collaborative group.

- Encouraging the culture of teacher as a reflective practitioner, who grows through experiences and taking risks. This can be done through dialogue, classroom experimentation coupled with self and group reflection.

- The professional digital portfolio can serve as an ideal forum to reflect, celebrate and share this learning.

\subsection{Money}

The CEO Forum on Education and Technology (1999) states that a minimum of $30 \%$ of a school's IT budget should be devoted to professional development. For a school this is reasonable if ICT use is successfully integrated; more is needed if not. But the figure is too low considering the cost of professional development courses and replacement costs for teachers. The problem is exacerbated in rural areas. A higher priority on the purchase of equipment often reduces funds for professional development. Some solutions to this dilemma could be student free days for whole staff training, clustering of schools and cost sharing, commercial or community partnerships, and online professional development.

\subsection{Aligning goals of assessment and CPD}

In the US and UK, the focus and motivation for teacher development is often related to perceived professional responsibilities and requirements. Many national assessment frameworks, 'high stakes' in expectations of teachers, do not require the integration of ICT to support learning and assessment objectives. Policies may request evidence that ICT is promoting achievement in traditional assessment objectives. Models for teacher professional development which are relevant and meaningful for teachers need to address how ICT developments relate to assessment frameworks for student and teacher performance, and which acknowledge issues of higherorder thinking, autonomy, collaboration, problem-solving and motivation. 
Strategies at systemic and local levels could include acknowledgement and legitimation of the evaluation of alternative assessment practices.

\subsection{Language barriers}

For countries where English is not the mother language, the language of ICT is an issue. Most ICT education programs are in English; software and manuals are in English. This creates barriers for leaders, teachers and students in learning with ICT. More than $95 \%$ of teachers in Sri Lanka received their school education and/or university education in their mother language (Sinhala or Tamil). Considering the nature of the subject and global requirements, the national ICT education policy proposes that the medium of instruction for ICT education should be English with some support in the native language. Providing ICT training in English is identified as an essential, but a very complicated task to be achieved. A policy proposal is to have special programs called 'English for IT' on top of the ICT Programs. With most of technical terms in English (no appropriate useable words in the native languages), a special TV program called ' IT Power for Teachers' is to be offered to all teachers across the island.

\subsection{Rewards and incentives}

Educational systems world-wide are exploring opportunities to provide incentives to teachers to encourage their use of ICT in classrooms. These incentives, coupled with a reward system for early adopters, acknowledge the work of teachers and counterbalance the general feelings of uncertainty and exhaustive demands placed on teachers. These incentives and rewards may take the form of advance standing in the teaching or monetary rewards through salary increments. In addition, systems may foster teacher development through the provision of hardware or grants for further study.

As an alternate reward, the issue of micro-payments are beginning to emerge. Although not obviously related to professional development, the innovative teacher who develops new resources and strategies often does so through accessing the more flexible aspects of CPD (i.e. listservs, texts, web or online courses) resulting in learning objects and practices developed primarily in the teachers own time. Micro-payments may be presented in many formats and ways. Should they be introduced? Much debate should ensure that an equitable approach to them be achieved. 


\section{CONCLUSIONS}

Even though the issues around teacher development and the integration of ICT in the classroom are challenging, there are numerous examples of solutions that have been designed and successfully implemented throughout the world. There is no one, short-term solution. There is a diversity of potential solutions for a diversity of needs, levels, and locations. The challenge is to learn from the diversity of the solutions. Pre-service teacher education and continuing professional development of all teachers as well as the educational leaders need on-going support at the highest levels.

\section{REFERENCES}

APEC (1999) Integration of information and communication technologies through teacher professional development. APEC workshop, December 1-3, Canada Forum, Toronto. [http://www.cmec.ca/international/forum].

CEO Forum on Education and Technology (1999) Professional development: A link to better learning. The CEO Forum on Education and Technology, Washington.

CERI (1998) Staying ahead: In-service training and teacher professional development. Centre for Educational Research and Innovation, Organisation for Economic Cooperation and Development.

Department of Education, Training and Youth Affairs (to be launched) Models of teacher professional development for the integration of ICTs into classroom practice. A Report to the Commonwealth Department of Education, Training and Youth Affairs.

Commonwealth of Australia, Canberra. Further details can be obtained from Toni Downes: t.downes@uws.edu.au.

Withange, D. (2001) National policy for IT education in Sri Lanka. Ministry of Education. [http://www.moesl.org/Policy/ITPolicy]. 